\title{
A question of balance: achieving appropriate nutrient levels in biofortified staple crops
}

\author{
Georgina Sanahuja ${ }^{1} \dagger$, Gemma Farré ${ }^{1} \dagger$, Judit Berman ${ }^{1}$, Uxue Zorrilla-López ${ }^{1}$, Richard M. Twyman ${ }^{2}$, \\ Teresa Capell $^{1}$, Paul Christou ${ }^{1,3}$ and Changfu Zhu ${ }^{1 *}$ \\ ${ }^{1}$ Departament de Producció Vegetal i Ciència Forestal, Universitat de Lleida-Agrotecnio Center, 25198 Lleida, Spain \\ ${ }^{2}$ TRM Ltd, PO Box 93, York YO43 3WE, UK \\ ${ }^{3}$ Institució Catalana de Recerca $i$ Estudis Avançats, 08010 Barcelona, Spain
}

\section{Abstract}

The biofortification of staple crops with vitamins is an attractive strategy to increase the nutritional quality of human food, particularly in areas where the population subsists on a cereal-based diet. Unlike other approaches, biofortification is sustainable and does not require anything more than a standard food-distribution infrastructure. The health-promoting effects of vitamins depend on overall intake and bioavailability, the latter influenced by food processing, absorption efficiency and the utilisation or retention of the vitamin in the body. The bioavailability of vitamins in nutritionally enriched foods should ideally be adjusted to achieve the dietary reference intake in a reasonable portion. Current vitamin biofortification programmes focus on the fat-soluble vitamins A and E, and the water-soluble vitamins $\mathrm{C}$ and $\mathrm{B}_{9}$ (folate), but the control of dosage and bioavailability has been largely overlooked. In the present review, we discuss the vitamin content of nutritionally enhanced foods developed by conventional breeding and genetic engineering, focusing on dosage and bioavailability. Although the biofortification of staple crops could potentially address micronutrient deficiency on a global scale, further research is required to develop effective strategies that match the bioavailability of vitamins to the requirements of the human diet.

Key words: Biofortification: Bioavailability: Dietary reference intake: Vitamins: Staple crops

\section{Introduction}

Up to one-third of the world's population is currently at risk from vitamin deficiency disorders, which can have a severe impact on metabolism resulting in cumulative damage to health $^{(1,2)}$. Strategies to address vitamin deficiency include the provision of supplements, the fortification of processed foods and the biofortification of crops to increase the vitamin content at source ${ }^{(3,4)}$. Health authorities in the developed world have established dietary reference intakes (DRI) for vitamins, which are based on recommended daily allowances (RDA) and tolerable upper levels (UL). The RDA is defined as the daily dietary intake level of a nutrient considered sufficient to meet the requirements of $97.5 \%$ of healthy individuals in each life-stage and sex group, and the UL is defined as the highest daily consumption that current data have shown to cause no side effects in humans ${ }^{(5,6)}$. For example, the RDA for vitamin A is $900 \mu \mathrm{g} / \mathrm{d}$ and the UL is $3000 \mu \mathrm{g} / \mathrm{d}$. Strategies that address vitamin deficiency must therefore strive to achieve the DRI for each vitamin without exceeding the UL.
Most strategies developed to address vitamin deficiency diseases focus on the total amount of vitamin provided rather than its bioavailability. The latter is important because many different factors affect the efficiency with which vitamins are taken up from food, including the nature of the food matrix, the manner in which the food is prepared and the efficiency with which available free vitamin molecules are absorbed in the human gut. Furthermore, some vitamins are absorbed as pro-vitamins which are converted into their final form in the human body. For example, vitamin A is generally absorbed either as retinol from meat and dairy sources or as $\beta$-carotene from plant sources, whereas the functional forms of vitamin A are retinal and retinoic acid. The US Institute of Medicine has therefore recommended that the DRI for vitamin A is expressed as retinol activity equivalents (RAE), which take bioavailability and metabolic conversion into account $^{(7,8)}$. Each RAE corresponds to $1 \mu \mathrm{g}$ of pure retinol in oil, $2 \mu \mathrm{g}$ of $\beta$-carotene in oil, $12 \mu \mathrm{g}$ of dietary $\beta$-carotene (accounting for the impact of the food matrix on

\footnotetext{
Abbreviations: DRI, dietary reference intake; RAE, retinol activity equivalent

*Corresponding author: Dr Changfu Zhu, email zhu@pvcf.udl.cat

tContributed equally to the present review.
} 
bioavailability) or $24 \mu \mathrm{g}$ of dietary $\alpha$-carotene, $\gamma$-carotene or $\beta$-cryptoxanthin, since these carotenoids carry only one active retinol group whereas $\beta$-carotene carries two ${ }^{(9)}$.

The DRI must also take into account the requirements of different life-stage and sex groups. As stated above, the DRI for vitamin A is $900 \mu \mathrm{g} / \mathrm{d}$ or 900 RAE. However, this is the value for adult males. The DRI for females is 700 RAE, rising to 770 RAE in pregnancy and 1300 RAE when lactating, and the DRI for children is 400-500 RAE depending on age $^{(7)}$. The DRI values for the four vitamins discussed in the present review are listed in Table 1, providing a breakdown by sex and life stage where appropriate. In some cases, the requirements are highly specific; for example, folate requirements increase from $400 \mu \mathrm{g} / \mathrm{d}$ for adult females to $600 \mu \mathrm{g} / \mathrm{d}$ during the first 12 weeks of pregnancy to reduce the risk of neural tube defects ${ }^{(10,11)}$. Folate is the form that occurs naturally in food sources, whereas folic acid is the form of the vitamin found in fortified foods and dietary supplements ${ }^{(12)}$.

A balanced and varied diet including fresh fruit, vegetables, fish and meat provides the DRI for all vitamins and other nutrients, but such diets are difficult to achieve in many developing-country settings because fresh food is either unavailable or too expensive for the majority of the population and the best that can be provided is a predominantly cereal-based diet ${ }^{(3,4)}$. Although fruits and vegetables are good sources of vitamins, cereals (particularly milled grains) are poor sources of many nutrients, despite providing adequate amounts of carbohydrate and protein. Micronutrient deficiency can be addressed by providing supplements or by fortifying processed foods such as flour with vitamins, but these approaches are generally unsustainable in developing countries because they require continuous investment, efficient government-level infrastructure for production and distribution, and local compliance to achieve adequate doses ${ }^{(13)}$. An alternative is the biofortification of cereal crops at source by enhancing their intrinsic levels of vitamins, which requires investment only at the development stage and can thereafter rely on existing food processing and distribution networks without specific strategies to ensure local compliance $^{(14-16)}$.

There has been significant recent progress in the biofortification of staple crops with vitamins, including the key examples of Golden Rice producing high levels of $\beta$-carotene ${ }^{(17)}$ and 'multivitamin corn' simultaneously producing high levels of $\beta$-carotene, ascorbic acid (vitamin C) and folate ${ }^{(18)}$. However, a large majority of the biofortification studies that have been published thus far have measured absolute levels of the enhanced vitamins without considering bioavailability, which will be critical for the success of biofortification programmes. Any biofortified crop deployed in the field will need to provide the DRI of each nutritional component in a reasonable portion, i.e. consistent with a standard daily food intake of $130-150 \mathrm{~g}$ of fruits and vegetables, up to $1.6 \mathrm{~g}$
Table 1. Dietary reference intakes (DRI) and tolerable upper intake levels (UL) for the four vitamins discussed in the review

\begin{tabular}{|c|c|c|c|c|c|c|}
\hline \multirow[b]{2}{*}{ Age } & \multicolumn{2}{|c|}{ Female/male } & \multicolumn{2}{|c|}{ Pregnancy } & \multicolumn{2}{|c|}{ Lactation } \\
\hline & $\mathrm{DRI}^{*}$ & UL† & $\mathrm{DRI}^{*}$ & UL† & $\mathrm{DRI}^{*}$ & UL† \\
\hline \multicolumn{7}{|c|}{ Vitamin Ał (mg/d) } \\
\hline $0-6$ months & 0.4 & 0.6 & - & - & _- & - \\
\hline $7-12$ months & 0.5 & 0.6 & - & - & - & - \\
\hline $1-3$ years & 0.3 & 0.6 & - & - & - & - \\
\hline $4-8$ years & 0.4 & 0.9 & - & - & - & - \\
\hline $9-13$ years & 0.6 & $1 \cdot 7$ & - & - & - & - \\
\hline $14+$ years & $0.7 / 0.9 \S$ & 3 & 0.77 & 3 & 1.3 & 3 \\
\hline \multicolumn{7}{|l|}{ Folate\|ी (mg/d) } \\
\hline $0-12$ months & $0.065-0.08$ & ND & - & - & - & - \\
\hline $1-3$ years & 0.15 & 0.3 & - & - & - & - \\
\hline $4-8$ years & 0.2 & 0.4 & - & - & - & - \\
\hline $9-13$ years & 0.3 & 0.6 & - & - & - & - \\
\hline $14+$ years & $0.4 \S$ & 1 & 0.6 & 1 & 0.5 & 1 \\
\hline \multicolumn{7}{|c|}{ Vitamin $E \|^{* *}(\mathrm{mg} / \mathrm{d})$} \\
\hline $0-12$ months & $4-5$ & ND & - & - & - & - \\
\hline $1-3$ years & 6 & 200 & - & - & - & - \\
\hline $4-8$ years & 7 & 300 & - & - & - & - \\
\hline $9-13$ years & 11 & 600 & - & - & - & - \\
\hline $14+$ years & $15 \S$ & 1000 & 15 & 1000 & 19 & 1000 \\
\hline \multicolumn{7}{|l|}{ Vitamin C $(\mathrm{mg} / \mathrm{d})$} \\
\hline $0-12$ months & $40-50$ & ND & - & - & - & - \\
\hline $1-3$ years & 15 & 400 & - & - & - & - \\
\hline $4-8$ years & 25 & 650 & - & - & - & - \\
\hline $9-13$ years & 45 & 1200 & - & - & - & - \\
\hline $14-18$ years & 75 & 1800 & 80 & 1800 & 115 & 1800 \\
\hline $19+$ years & $90 \S$ & 2000 & 85 & 2000 & 120 & 2000 \\
\hline
\end{tabular}

ND, not determinable due to lack of data of adverse effects in this age group and concern with regard to lack of ability to handle excess amounts. Source of intake should be from food only to prevent high levels of intake. EAR, estimated average requirement; DFE, dietary folic acid equivalents.

* The DRI is based on the older recommended daily intake, which is the average daily intake sufficient to meet the requirements of $97.5 \%$ of healthy individuals. It is calculated from an EAR. If sufficient evidence is not available to establish the EAR, an adequate intake may be used instead, which is the mean intake for healthy breastfed infants or that sufficient to cover the needs of all healthy individuals in other life-stage and sex groups, accepting uncertainty in the percentage of individuals covered by this intake. DRI taken from the DRI reports; see Dietary Reference Intakes for Folate ${ }^{(119)}$ and Dietary Reference Intakes for Vitamin $C$, Vitamin $E^{(7)}$

†UL is the highest level of daily nutrient intake that is likely to pose no risk of adverse health effects to almost all individuals in the general population. Unless otherwise specified, the UL represents total intake from food, water and supplements. In the absence of an UL, extra caution may be warranted in consuming levels above recommended intakes. Members of the general population are advised not to exceed the UL routinely. The UL is not meant to apply to individuals who are treated with the nutrient under medical supervision or to individuals with predisposing conditions that modify their sensitivity to the nutrient. UL is adapted from Institute of Medicine ${ }^{(8)}$

$\ddagger$ As preformed vitamin A only.

$\S D R I$ for the four vitamins discussed in the present review.

$\|$ As dietary DFE. $1 \mathrm{DFE}=1 \mu \mathrm{g}$ food folic acid $=0.6 \mu \mathrm{g}$ of folic acid from fortified food or as a supplement consumed with food $=0.5 \mu \mathrm{g}$ of a supplement taken on an empty stomach.

I The UL for vitamin E and UL for folic acid apply to synthetic forms obtained from supplements, fortified foods, or a combination of the two.

${ }^{* *}$ As $\alpha$-tocopherol, which includes RRR- $\alpha$-tocopherol, the only form of $\alpha$-tocopherol that occurs naturally in foods, and the $2 R$-stereoisomeric forms of $\alpha$-tocopherol (RRR-, RSR-, RRS-, and RSS- $\alpha$-tocopherol) that occur in fortified foods and supplements. It does not include the 2S-stereoisomeric forms of $\alpha$-tocopherol (SRR-, SSR-, SRS-, and SSS- $\alpha$-tocopherol), also found in fortified foods and supplements.

of oil and up to $350 \mathrm{~g}$ of rice ${ }^{(19)}$. However, the dosage must also take into account the impact of food processing, cooking and co-dietary factors such as the consumption of nutritional promoters and inhibitors. One final significant challenge is that these ideal dosage levels must be achieved for different vitamins simultaneously to avoid 
merely shifting the challenge of micronutrient deficiency from one set of nutrients to another ${ }^{(2,18)}$.

The impact of food processing on vitamin levels and bioavailability in food

\section{Fat-soluble vitamins}

The stability of carotenoids differs according to the properties of the food matrix even when the same processing and storage conditions are used ${ }^{(20)}$. However, the processing method also has a significant impact. For example, some $\beta$-carotene is lost during microwaving, steaming, boiling and sautéing, but much more substantial losses occur during deep-frying, prolonged cooking, and combinations of several preparation or processing methods such as baking and pickling ${ }^{(20)}$. Whereas almost all cooking methods reduce the overall content of $\beta$-carotene, some simultaneously increase its bioavailability by releasing it from the food matrix ${ }^{(21)}$. Products that are often consumed raw (for example, carrots, tomatoes and other fruits) may therefore be less suitable sources of $\beta$-carotene than cereals, potatoes and rapeseed oil, which are cooked before consumption, even though the overall levels are higher before cooking. For example, although microwave cooking reduces the overall amount of $\beta$-carotene it also increases tissue degradation and the amount of $\beta$-carotene available for extraction $^{(22)}$. These factors explain why only minor changes in $\beta$-carotene levels were observed in tomato juice during processing ${ }^{(23)}$ whereas the levels of bioavailable $\beta$-carotene can increase or decrease in carrots and cassava depending on the cooking method ${ }^{(24,25)}$.

Vitamin E is a group of related compounds known as tocochromanols, which are divided into the tocopherols and tocotrienols. Vitamin E levels in cereals are also affected by storage and cooking, but there are conflicting reports in the literature suggesting that the bioavailable levels increase, decrease or do not change ${ }^{(26,27)}$. Minimal losses were recorded when cereal grains were stored under optimal conditions in the absence of insect pests, but processing by milling resulted in significant losses ${ }^{(28,29)}$. Furthermore, the tocochromanol levels in wheat, barley and oats were reported to fall by $30 \%$ during extrusion cooking ${ }^{(30)}$, whereas cooking in water was shown to increase the total tocochromanol levels in red and white rice by 32 and $37 \%$, respectively ${ }^{(31)}$. Importantly, this increase reflected the $23 \%$ loss of soluble DM during water cooking which resulted in the concentration of lipophilic compounds ${ }^{(31)}$. Such reports demonstrate the importance of standardised methods for measuring and recording nutritional components in foods to allow direct and meaningful comparisons.

The processing of plant oils can also reduce the availability of tocochromanols, for example, pre-heating, cooking and screw-pressing can reduce levels by $15 \%$ in olive oil, $25 \%$ in soyabean and rapeseed oils, $28.5 \%$ in high-oleic safflower-seed oil, $32 \%$ in maize oil and $35-40 \%$ in cottonseed and groundnut oil ${ }^{(32,33)}$.

\section{Water-soluble vitamins}

Vitamin $\mathrm{C}$ is also lost during cooking, but the amount depends on the temperature, the degree of leaching into the cooking medium, the surface area of the food exposed to water, oxygen levels, $\mathrm{pH}$, and the presence of prooxidation factors ${ }^{(34)}$. Vitamin $\mathrm{C}$ in potatoes is rapidly degraded during boiling and frying, but is less susceptible during braising, sautéing and pressure-cooking, and only minimal losses occur during baking and microwaving ${ }^{(35)}$ In addition, boiling in salted water can offer partial protection from degradation $^{(35)}$.

The levels of plasma vitamin $\mathrm{C}$ were measured in human subjects after the consumption of either fresh strawberries or strawberries stored in an open container at $4^{\circ} \mathrm{C}$ for $4 \mathrm{~d}$. Although the levels of ascorbic acid in the fruits were the same, the plasma ascorbic acid levels were higher in subjects who had consumed the stored strawberries, which was attributed to the modification of bioactive compounds that influence the bioavailability of ascorbic acid ${ }^{(36)}$

Folate is also lost during cooking and food preparation, reflecting a combination of thermal degradation and leaching into the cooking water ${ }^{(37)}$. Leaching was found to be the major factor; for example, boiling in water reduced the folate content of broccoli and peas more than blanching and microwaving, whereas minimal losses were recorded after steaming, which involves the least contact with water ${ }^{(38)}$. The boiling of peeled and unpeeled potatoes resulted in folate losses of 52 and $37 \%$, respectively, suggesting that the skin protects against folate loss ${ }^{(38)}$. This also indicated the greater role of leaching compared with thermal degradation in the loss of folate ${ }^{(39,40)}$.

\section{Vitamin biofortification to improve nutrition}

As discussed above, the biofortification of crops at source provides a sustainable approach to improve the nutritional quality of food without the continual need for a specialised distribution infrastructure or compliance monitoring ${ }^{(13,15)}$ Two strategies have been developed to increase the vitamin levels in plants: one involving conventional breeding and the other involving genetic engineering.

Numerous studies have shown that so far only genetic engineering has provided the means to produce nutritionally enhanced crops that can meet DRI values. For example, different genetic engineering strategies have yielded tomato fruits producing (in separate plants individually) up to $205 \mu \mathrm{g}$ of $\beta$-carotene/g fresh weight ${ }^{(41)}, 1159 \mu \mathrm{g}$ of ascorbic acid/g fresh weight ${ }^{(42)}, 10 \mu \mathrm{g}$ of folate/g fresh weight ${ }^{(43)}$ or $4.57 \mu \mathrm{g}$ of $\alpha$-tocopherol $/ \mathrm{g}$ fresh weight ${ }^{(44)}$. In contrast, conventional breeding in different tomato varieties has achieved maximum levels of $20 \mu \mathrm{g}$ of $\beta$-carotene/g fresh weight $^{(45)}, 180 \mu \mathrm{g}$ of ascorbic acid/g fresh weight ${ }^{(46)}$ or 
$0 \cdot 29 \mu \mathrm{g}$ of folate/g fresh weight ${ }^{(47)}$. Focusing on $\beta$-carotene, the difference in achievement therefore equates to $28 \%$ of the DRI in conventionally bred tomatoes ${ }^{(45)}$ compared with $285 \%$ of the DRI in tomato lines produced by genetic engineering ${ }^{(41)}$. This means that the genetically engineered tomatoes would be required as minor food additives rather than whole fruit in order to achieve the DRI. We provide a breakdown of the nutritional values of other conventional and genetically engineered crops in online Supplementary Table S1.

Most of the nutritionally enhanced crops reported thus far produce higher levels of a single vitamin, and can therefore be regarded as targeted intervention crops suitable for populations with particular nutrient deficiencies ${ }^{(13,48)}$. However, many populations in developing country suffer from multiple nutrient deficiencies simultaneously, and in the future it will be necessary to develop staple crops providing the DRI for several vitamins and other nutrients in one variety (see the Multivitamin-enhanced crops section). Again, this is beyond the abilities of conventional breeding, since each additional nutritional trait would require individual selection followed by introgression into existing nutritionally enhanced locally adapted varieties. In contrast, it is possible to introduce multiple genes directly into local cultivars by genetic engineering in order to enhance different nutritional components simultaneously ${ }^{(18)}$. Only one such report has been published thus far, describing a genetically engineered maize line producing higher levels of ascorbic acid, $\beta$-carotene and folate ${ }^{(18)}$. This was achieved by combinatorial nuclear transformation with genes representing the three separate metabolic pathways ${ }^{(49)}$. The adoption of staple crops producing higher levels of multiple nutrients will help to improve the health and well-being of the world's poorest individuals.

\section{Hypervitaminosis}

Tolerable upper limits have been established for most vitamins, including the four discussed in the present review (Table 1 ).

Water-soluble vitamins must be ingested daily because they cannot be stored in the body. Therefore, although tolerable upper limits have been proposed for ascorbic acid and folate, it is unusual to see clinical effects unless there is contraindication with metabolically related drugs. For example, the tolerable upper limit for ascorbic acid is $2000 \mathrm{mg} / \mathrm{d}$, but an intake of $>100 \mathrm{mg}$ results in rapid excretion in the urine without harmful effects ${ }^{(50,51)}$. Similarly the tolerable upper limit for folate is $1 \mathrm{mg} / \mathrm{d}$ for adults, but there is no consensus about what blood concentrations of folate might cause harm ${ }^{(52)}$. In contrast, fat-soluble vitamins are stored in the body and overdosing can cause harmful effects. In adults, the tolerable upper limit for vitamin A is $3 \mathrm{mg} / \mathrm{d}$, and clinical studies have shown that acute doses above this limit or chronic doses of $7 \cdot 5-15 \mathrm{mg} / \mathrm{d}$ can induce anorexia, headaches, nausea and muscle weakness in the short term ${ }^{(53)}$ and osteoporosis in the long term ${ }^{(54)}$. The tolerable upper limit for vitamin $\mathrm{E}$ in adults is $1 \mathrm{~g} / \mathrm{d}$, and although no harmful effects have been observed from acute doses of up to $3 \cdot 2 \mathrm{~g} / \mathrm{d}$, overdosing can exacerbate the blood coagulation defect of vitamin $\mathrm{K}$ deficiency caused by malabsorption or anticoagulant therapy. High levels of vitamin $\mathrm{E}$ are therefore contraindicated in these subjects ${ }^{(55,56)}$

The concept of a tolerable upper level for vitamins is pertinent only for vitamin supplements because it is difficult to ingest toxic levels of vitamins with a natural diet, although excess levels of the fat-soluble vitamins can be reached through the overconsumption of highly fortified processed food ${ }^{(57)}$. However, nutritionally enhanced crops are subject to appropriate nutritional and feeding studies before commercialisation. All genetically engineered crops undergo rigorous risk assessment to ascertain their potential impact on human health and the environment before they receive market authorisation ${ }^{(58)}$. In addition, genetically engineered crops must undergo toxicological analysis to demonstrate the absence of unintended effects using animal models (usually rodents) and this may be extended from acute tests to multigenerational chronic toxicity/reproductive tests on a case-by-case basis ${ }^{(59)}$. The best-known example of a nutritionally enhanced crop is Golden Rice with the successful completion of multiple safety assessment in silico, in vitro, in animals and in human trials ${ }^{(60)}$. Another more recent example is 'multivitamin corn', which was tested in animal feeding studies for sub-chronic toxicity. No indications of toxicity were evident compared with animals fed on control diets. The study thus confirmed that diets enriched with 'multivitamin corn' did not have any adverse effects on mice, did not induce any clinical signs of toxicity and did not contain known allergens ${ }^{(61)}$.

\section{Multivitamin-enhanced crops}

The biofortification of local elite crop varieties with multiple vitamins will require a combination of breeding and genetic engineering. Breeding alone cannot be used to produce nutritionally complete crops because the selection process is too complex ${ }^{(18,62,63)}$. Thus far, one genetically engineered 'multivitamin corn' variety has been described $^{(18)}$ and this was simultaneously enhanced for three different vitamins (ascorbic acid, $\beta$-carotene and folate). Online Supplementary Table S2 shows the percentage of DRI provided by the best-performing transgenic crops enhanced with the vitamins discussed in the present review. Ideally, it would be useful to combine these traits so that a single portion could meet the DRI for all vitamins, for example, a transgenic tomato providing $950 \mu \mathrm{g}$ of $\beta$-carotene $/ g$ fresh weight, $1159 \mu \mathrm{g}$ of ascorbic acid $/ \mathrm{g}$ fresh weight, $11.04 \mu \mathrm{g}$ of folate/g fresh weight and $4.57 \mu \mathrm{g}$ of $\alpha$-tocopherol/g fresh weight (see online Supplementary Table S2). In maize, the best-performing 
transgenic lines developed thus far yield $59.3 \mu \mathrm{g}$ of $\beta$-carotene $/ g$ dry weight, $344.75 \mu \mathrm{g}$ of $\alpha$-tocopherol $/ \mathrm{g}$ dry weight, $1.94 \mu \mathrm{g}$ of folate/g dry weight and $168 \mu \mathrm{g}$ of ascorbic acid/g dry weight.

\section{Processing of biofortified crops}

Few studies have considered the bioavailability of $\beta$-carotene in genetically engineered staple crops after processing. In the case of Golden Rice, which accumulates $31 \mu \mathrm{g} / \mathrm{g}$ dry weight of grain by overexpressing the enzymes phytoene synthase (PSY1) and carotene desaturase to remove an early bottleneck in the carotenoid biosynthesis pathway ${ }^{(17)}$, the total amount of $\beta$-carotene was found to be the same before and after cooking ${ }^{(60)}$. A small-scale study with Golden Rice fed to US adults showed efficient bioconversion of $\beta$-carotene to vitamin $A^{(60)}$. The study indicated that $3.8 \mu \mathrm{g} \quad \beta$-carotene delivered as Golden Rice provides $1 \mu \mathrm{g}$ retinol. The amount of $\beta$-carotene in Golden Rice is $20-30 \mu \mathrm{g} / \mathrm{g}$ uncooked rice; consequently $100 \mathrm{~g}$ uncooked rice provides $500-800 \mu \mathrm{g}$ retinol $^{(60)}$. Another trial compared the vitamin A value of Golden Rice with that of spinach and pure $\beta$-carotene in oil, in schoolchildren of marginal or normal vitamin A status $^{(64)}$. The study concluded that $\beta$-carotene in Golden Rice is as effective as pure $\beta$-carotene in oil and better than that in spinach at providing vitamin A to children ${ }^{(64)}$.

In transgenic potatoes expressing the Orange (Or) gene, which leads to the induction of chromoplast development thus creating a metabolic sink for carotenoids, the levels of $\beta$-carotene were five-fold higher than in normal potatoes at harvest, i.e. $5 \mu \mathrm{g} \beta$-carotene/g dry tuber weight ${ }^{(65)}$, but this increased to 10 -fold higher when the tubers were stored at $5^{\circ} \mathrm{C}$ for 6 months ${ }^{(66)}$.

The impact of processing on nutritionally enhanced foods can be predicted by extrapolating the effect of processing on normal foods, i.e. the percentage loss or gain of bioavailable vitamin resulting from different processing methods. For example, baking tomatoes at $160^{\circ} \mathrm{C}$ for $20 \mathrm{~min}$ increases the bioavailable $\beta$-carotene content by $81 \%{ }^{(67)}$ whereas canned tomato juice contains $20 \%$ less $\beta$-carotene than fresh tomatoes ${ }^{(68)}$. Therefore, if we take the best-performing genetically enhanced tomato line, which produces $205 \mu \mathrm{g}$ of $\beta$-carotene/g in the fresh tomato fruits ${ }^{(41)}$, we can predict that a reasonable portion of tomatoes $(150 \mathrm{~g} / \mathrm{d})$ would provide $285 \%$ of the DRI for vitamin A when consumed as fresh fruit, 516\% when consumed after baking and $222 \%$ as processed tomato juice (see online Supplementary Table S1).

Similarly, $\beta$-carotene levels in carrots fall by 16 and $59 \%$ after conventional cooking for 10 and $60 \mathrm{~min}$, respectively $^{(24,69)}$, and by $27 \%$ after pressure-cooking for $10 \mathrm{~min}^{(22)}$. Puréeing reduces $\beta$-carotene levels by $56 \%{ }^{(70)}$ and carrot juice contains $23 \%$ less $\beta$-carotene than fresh carrots $^{(71)}$. Therefore, the best transgenic carrot variety, which produces $39 \mu \mathrm{g}$ of $\beta$-carotene/g fresh weight ${ }^{(72)}$, would achieve $54 \%$ of the DRI for vitamin A if $150 \mathrm{~g} / \mathrm{d}$ were consumed as raw vegetables and $22 \%$ if cooked for $60 \mathrm{~min}$, compared with conventional carrots which achieve 0.2 or $0.09 \%$ if consumed raw or cooked for $60 \mathrm{~min}$, respectively (see online Supplementary Table S1).

The highest level of vitamin $\mathrm{E}$ produced thus far in transgenic tomatoes is $4.57 \mu \mathrm{g} / \mathrm{g}$ fresh weight, which is equivalent to $5 \%$ of the DRI assuming a portion of $150 \mathrm{~g} / \mathrm{d}^{(44)}$. Transgenic lettuce plants have been produced yielding up to $64.55 \mu \mathrm{g}$ of vitamin $\mathrm{E} / \mathrm{g}$ fresh weight, which assuming the same portion size would be equivalent to $64 \%$ of the $\mathrm{DRI}^{(73)}$. Food processing has a small but significant impact on vitamin E levels; for example, microwaving reduces overall vitamin E levels in soyabean oil by $10 \%{ }^{(74)}$ and cooking for 165 min reduces vitamin $\mathrm{E}$ levels by $8 \%{ }^{(75)}$.

The impact of processing on water-soluble vitamins is more potent. Transgenic tomatoes, lettuce and strawberries have been developed containing up to 1159, 792 and $1303 \mu \mathrm{g}$ of vitamin $\mathrm{C} / \mathrm{g}$ fresh weight, respectively ${ }^{(42,76,77)}$. These values represent 193, 133 and $217 \%$ of the DRI for vitamin $\mathrm{C}$ assuming a daily portion of $150 \mathrm{~g}$ (see online Supplementary Table S1). However, up to $89 \%$ of the vitamin $\mathrm{C}$ in tomatoes is lost by cooking, reducing its nutritional value to $21 \%$ of the $\mathrm{DRI}^{(78)}$. Transgenic potatoes have been produced yielding $915 \mu \mathrm{g}$ of vitamin C/g fresh weight, which is equivalent to $133 \%$ of the DRI for vitamin $\mathrm{C}$ assuming a daily portion of $130 \mathrm{~g}^{(79)}$. However, vitamin C is particularly susceptible during wet cooking methods and $20-40 \%$ is lost; even dry cooking methods such as microwaving reduce vitamin $\mathrm{C}$ levels by $8-17 \%{ }^{(80)}$. Therefore, if the transgenic potatoes described above were prepared by conventional cooking, pressure-cooking or microwaving, the vitamin $\mathrm{C}$ content of a daily portion would be reduced to 80,90 and $110 \%$ of the DRI, respectively (see online Supplementary Table S1).

Transgenic tomato and lettuce plants have been produced yielding 10 and $1.89 \mu \mathrm{g}$ of folate/g fresh weight, respectively ${ }^{(43,81)}$. Although, as discussed above, folate is lost by leaching during processing, both tomatoes and lettuce tend to be eaten fresh and portions of $150 \mathrm{~g} / \mathrm{d}$ would achieve 380 and $71 \%$ of the DRI, respectively (see online Supplementary Table S1).

Maize is a particularly interesting example to investigate because in this case it is possible to predict the nutritional values of three different vitamins in one meal of 100-200 g of grain (a typical portion). The carotenoid content of maize is reduced by more than $50 \%$ by lime-cooking ${ }^{(82)}$, which means that a portion of 'multivitamin corn',(18) would provide $35 \%$ of the DRI for vitamin A when prepared in this manner. 'Multivitamin corn' also yields $106 \mu \mathrm{g}$ of vitamin C/g dry weight and $1.94 \mu \mathrm{g}$ of folate $/ \mathrm{g}$ dry weight ${ }^{(18)}$ but there are no data in the literature to show how these levels would be affected by storage, processing and cooking. 


\section{Efficiency of vitamin absorption}

\section{Fat-soluble vitamins}

The absorption, transport and distribution of vitamins A and $\mathrm{E}$ within the body are linked to the intake of dietary fat $^{(83,84)}$. The amount of fat ingested in the meal plays a crucial role because it may promote carotenoid absorption by stimulating bile secretion and increasing the luminal concentration of bile salts, which act as surfactants in the formation of mixed micelles ${ }^{(85)}$. The bioavailability of vitamin $\mathrm{E}$ also depends on the amount of fat ingested with the meal $^{(86)}$. There is no specific recommended dose of fat to promote vitamin adsorption ${ }^{(84)}$ and dietary compounds that inhibit fat absorption and facilitate its excretion from the body such as plant fibres and sterols have the opposite effect on vitamin bioavailability ${ }^{(87)}$.

During absorption, the first step is the release of vitamins from the food matrix, which is strongly influenced by different food processing techniques as discussed earlier. The type of food and the subcellular compartment containing the vitamin also has an impact, particularly in the case of $\beta$-carotene: plasma retinol levels are up to six times higher following the consumption of fruits compared with leafy vegetables containing the same overall amount of $\beta$-carotene, suggesting that it is released more easily from chromoplasts than chloroplasts ${ }^{(88)}$. The molecular structure of each type of vitamin influences its absorption. Hydrocarbonrich carotenoids such as $\beta$-carotene are less bioavailable than oxygenated carotenoids (for example, lutein) because the latter are easily incorporated into the outer portions of lipid micelles within the gastrointestinal tract and by enterocyte membranes ${ }^{(89)}$. In the case of tocopherols, all isomers can be absorbed equally during digestion ${ }^{(90)}$ but once chylomicrons reach the liver, the hepatic $\alpha$-tocopherol transfer protein preferentially retains $\alpha$-tocopherol, making it the most important isomer in terms of vitamin $\mathrm{E}$ activity ${ }^{(91)}$.

Vitamin A activity in the diet derives from two sources: preformed vitamin A as retinyl esters in foods of animal origin and provitamin A carotenoids, such as $\beta$-carotene, $\alpha$-carotene and $\beta$-cryptoxanthin, found in plant-derived foods ${ }^{(92)}$. In vivo studies showed that intestinal absorption of carotenoids involves several crucial steps: release from the food matrix, solubilisation into mixed lipid micelles in the lumen, cellular uptake by intestinal mucosal cells $^{(92-97)}$, incorporation into chylomicrons and secretion of carotenoids and their metabolites associated with chylomicrons into the $\operatorname{lymph}^{(92)}$ (Fig. 1). Intestinal cells take up carotenoids by facilitated processes involving scavenger receptor class $\mathrm{B}(\mathrm{SR}-\mathrm{BI})^{(92,93)}$. This receptor facilitates the intestinal absorption not only of $\beta$-carotene ${ }^{(94)}$, but also of fatty acids, cholesterol, vitamin $\mathrm{E}$ and non-provitamin A carotenoids ${ }^{(95-97)}$. Studies in mice have shown that elevated intestinal SR-BI levels accompany enhanced absorption of cholesterol and fatty acids ${ }^{(96)}$.

Vitamin E is not only solubilised in micelles but it is also distributed among different lipid structures (vesicles) in the intestinal lumen during digestion ${ }^{(98)}$. Absorption mechanisms seem to be affected by the cellular structure(s) with which vitamin $\mathrm{E}$ is associated: micelles may interact with proteins located in membranes, while vesicles might have a different transport pathway ${ }^{(98)}$. Intestinal absorption of vitamin $\mathrm{E}$ was assumed to occur by passive diffusion involving different proteins (Fig. 1) ${ }^{(99-102)}$. The efficiency of vitamin $\mathrm{E}$ absorption is maximal where the intestinal transporters of vitamin $\mathrm{E}$ are most highly expressed. In the intestinal cells, the main fraction is secreted into chylomicrons which are released from enterocytes into the lymphatic system and later the circulation en route to the liver ${ }^{(103)}$ (Fig. 1). Fat-soluble vitamins become associated with fat-transport proteins such as the various lipoprotein receptors that facilitate their distribution around the body ${ }^{(92,98)}$.

\section{Water-soluble vitamins}

Unlike fat-soluble vitamins, water-soluble vitamins must be ingested daily as they cannot be stored in the body. Although ascorbic acid is the principal active form of vitamin $\mathrm{C}$, dehydroascorbic acid also has some activity and the two can easily be interconverted so it is important to consider them both in bioavailability studies ${ }^{(104)}$. The different forms of vitamin $\mathrm{C}$ are absorbed by enterocytes via $\mathrm{Na}$-dependent transporters (reflecting the differential concentration of $\mathrm{Na}$ ions across the plasma membrane, maintained by $\mathrm{Na}^{+} / \mathrm{K}^{+}$-ATPases) or via facilitated diffusion mediated by GLUT transporters, although high intracellular glucose levels can inhibit this process ${ }^{(105)}$. Within the enterocyte, dehydroascorbic acid is reduced to ascorbic acid (Fig. 1), which leaves the cell at the basal membrane by an unknown mechanism ${ }^{(106)}$. Ascorbic acid is taken up into target cells via specific transporters ${ }^{(106)}$. Ascorbic acid can also be reabsorbed by renal tube cells ${ }^{(107)}$.

Folate is generally presented in the diet as polyglutamyl folate, which must be deconjugated by enzymes tethered to the intestinal epithelium before absorption by passive diffusion (if present at concentrations greater than $5-10 \mathrm{mmol} / \mathrm{l}$ ) or otherwise by a concentration-dependent specific transport process ${ }^{(108)}$ (Fig. 1). The monoglutamyl: polyglutamyl folate ratio in the diet appears to have no influence on the efficiency of absorption, suggesting that the enzymic deconjugation is not a rate-limiting step ${ }^{(109)}$. However, the entrapment of folate in food matrices can influence bioavailability by rendering it inaccessible to the epithelial enzymes ${ }^{(110)}$. In this context, the consumption of a folate tracer with a light breakfast meal reduced bioavailability by $15 \%$ compared with the folate tracer alone $^{(111)}$. Folate bioavailability can be increased by enhancing the activity of $\boldsymbol{\gamma}$-glutamyl hydrolase in plants, as this would be released from the vacuole following maceration and would promote the release of unconjugated folate from the food matrix before ingestion ${ }^{(110)}$. 


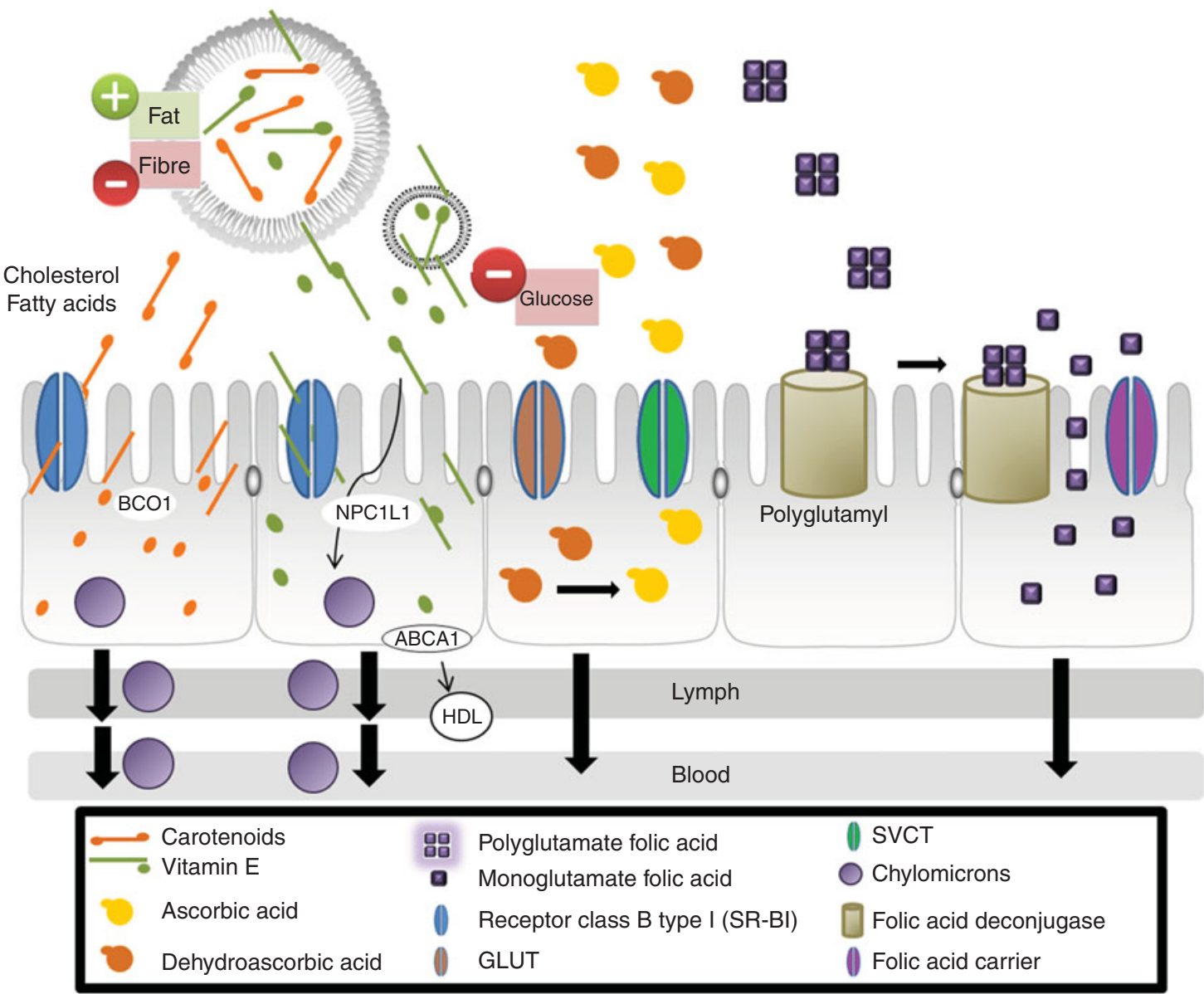

Fig. 1. Mechanisms for the absorption of carotenoids, vitamin $E$, vitamin $C$ and folate in the human body (modified substantially from Yonekura \& Nagao ${ }^{(103)}$ ). The first step is the release of vitamins from the food matrix. Dietary provitamin A carotenoids (for example, $\beta$-carotene) and other carotenoids are taken up by intestinal cells by processes involving scavenger receptor class B type I (SR-BI) ${ }^{(92,93)}$. SR-BI facilitates the intestinal absorption not only of $\beta$-carotene ${ }^{(94)}$, but also of fatty acids, cholesterol, vitamin $E$ and non-provitamin $A$ carotenoids ${ }^{(95-97)}$. Thus, $\beta$-carotene is partially converted to retinol by $\beta$-carotene oxygenase 1 (BCO1) and retinal reductase ${ }^{(93)}$. The retinol so formed is then metabolised in the same manner as that originating from preformed vitamin $A$. The intact carotenoids are incorporated into nascent chylomicrons. Chylomicrons containing newly absorbed retinyl esters (from animal origin) and carotenoids (from plant-derived food) are then secreted into the lymph. Vitamin $\mathrm{E}$ is solubilised in micelles and also is distributed between different lipid structures (vesicles). Absorption mechanisms are affected by the structure with which vitamin $E$ is associated. Intestinal absorption of vitamin $E$ was assumed to occur by passive diffusion: the transport of vitamin $\mathrm{E}$ was found to be non-ATP-dependent and also involve a membrane protein in the cellular uptake of vitamin $\mathrm{E}$, SR-BI ${ }^{(99)}$. More recent studies demonstrated that Niemann-Pick C1-like 1 (NPC1L1) protein is involved in vitamin E uptake at the apical membrane of the intestinal cell. Another protein, ATP binding cassette, subfamily A (ABCA1), is involved in vitamin E secretion at the basolateral side ${ }^{(100-102)}$. $\alpha$-Tocopherol is secreted by $A B C A 1$ that transports cellular cholesterol and phospholipids to lipid-poor HDL into the cells ${ }^{(102)}$. In the intestinal cells, the main fraction is secreted into chylomicrons which are released from enterocytes into the lymphatic system and later the circulation en route to the liver ${ }^{(100)}$. Both forms of vitamin $C$ are absorbed by enterocytes and transported to target cells ${ }^{(106)}$. Ascorbic acid is absorbed via Na-dependent vitamin C transporter (SVCT) while dehydroascorbic acid is absorbed via facilitative GLUT transporters. Polyglutamyl folates in the diet must be deconjugated by enzymes tethered to the intestinal epithelium before absorption ${ }^{(113)}$. (A colour version of this figure can be found online at http://www.journals.cambridge.org/nrr).

Folate is also absorbed in the colon, which is a site of folate synthesis by gut bacteria $^{(112)}$. Absorbed folate is transported to the liver, which contains approximately half the folate pool in the body ${ }^{(113)}$ and retains $10-20 \%$ of absorbed folate due to the first-pass effect ${ }^{(114)}$. The remainder is transported through the vasculature to the rest of the body. Some liver folate participates in the enterohepatic circulation and is secreted into the bile ${ }^{(115)}$

\section{Conclusions and perspectives}

Vitamins are essential nutrients that play specific roles in metabolism and a DRI level has been established to promote nutritional health and reduce the likelihood of micronutrient deficiency ${ }^{(34)}$. Fruits and vegetables provide adequate sources of vitamins, but large parts of the developing world have insufficient access to such foods and rely instead on a monotonous cereal-based diet ${ }^{(15)}$. Although nutritional health can be maintained by the provision of supplements or fortified processed foods, these are expensive and unsustainable practices that require government-level intervention and continuous funding. Biofortification is an alternative strategy that is sustainable because the vitamins are produced at source by the crops, thus allowing the distribution of nutritionally enhanced staple foods via established food distribution networks ${ }^{(4,116)}$. 
Although there has been recent progress in the development of genetically engineered biofortified crops, most studies have focused on the total vitamin content of the crops and have overlooked the impact of bioavailability which determines whether such crops could achieve the DRI for each vitamin in a reasonable portion. The bioavailable amount of vitamins depends on the food matrix, the processing and cooking methods, and co-dietary factors. Different food preparation methods can reduce the total levels of vitamins by thermal degradation and/or leaching, but may also increase vitamin bioavailability by partially degrading the food matrix and therefore improving accessibility ${ }^{(34)}$.

We have considered the overall improvement in vitamin levels achieved by genetic engineering and compared these with DRI values for fresh produce and portions prepared using different cooking methods. This is an important element in the development of nutritionally enhanced staple crops targeting specific developing country populations because the value of such products would depend on the inclusion of traditional cooking methods when calculating the impact on DRI. Our data suggest that most of the nutritionally enhanced crops developed thus far provide an improvement over conventional crops in terms of DRI even after food processing (see online Supplementary Table S2; see the Multivitamin-enhanced crops section) but their efficacy (biological impact under controlled conditions) and effectiveness (biological impact in real life) need to be evaluated further.

From an economic perspective, biofortified crops are likely to be more cost-effective than supplementation or conventional fortification ${ }^{(4,117)}$. However, this will only be the case if such crops achieve the DRI for target vitamins in a reasonable portion, otherwise supplementation and conventional fortification will need to be implemented alongside in order to address concurrent micronutrient deficiencies. If these conditions can be met, then nutritionally enhanced crops will provide a sustainable and economically viable approach to address the challenge of micronutrient deficiency in developing countries $^{(118)}$.

Further studies will be required to determine whether biofortified crops maintain their enhanced nutritional value in local agricultural environments. The varieties must also perform well in terms of yield and pest resistance in order to perform well economically and therefore gain acceptance from farmers and consumers. The introduction of new varieties must take into account the potential impact on local markets and on the local agricultural system, because biofortified varieties may attract a market premium that could encourage farmers to adopt the biofortified variety as a marketable commodity. The development of a viable and sustainable humanitarian product must not be derailed by poor economic performance and negative public perception.

\section{Supplementary Material}

To view supplementary material for this article, please visit http://dx.doi.org/10.1017/S0954422413000176

\section{Acknowledgements}

Research at the Universitat de Lleida is supported by MICINN (Ministerio de Ciencia e Innovacion), Spain (BIO2011-23324; BIO02011-22525; PIM2010PKB-00746); European Union Framework 7 Program-SmartCell Integrated Project 222716; European Union Framework 7 European Research Council IDEAS Advanced Grant (to P. C.) Program-BIOFORCE; COST Action FA0804: Molecular farming: plants as a production platform for high value proteins; Centre CONSOLIDER on Agrigenomics funded by MICINN, Spain and RecerCaixa.

P. C., T. C. and C. Z. conceived of and designed the review. All authors wrote the paper.

The authors declare that there are no conflicts of interest.

\section{References}

1. Farré G, Twyman RM, Zhu C, et al. (2011) Nutritionally enhanced crops and food security: scientific achievements versus political expediency. Curr Opin Biotechnol 22, 245-251.

2. Yuan D, Bassie L, Sabalza M, et al. (2011) The potential impact of plant biotechnology on the Millennium Development Goals. Plant Cell Rep 30, 249-265.

3. Zhu Z, Naqvi S, Gómez-Galera S, et al. (2007) Transgenic strategies for the nutritional enhancement of plants. Trends Plant Sci 12, 548-555.

4. Gómez-Galera S, Rojas E, Sudhakar D, et al. (2010) Critical evaluation of strategies for mineral fortification of staple crops. Transgenic Res 19, 165-180.

5. Institute of Medicine (2000) Dietary Reference Intakes. Applications in Dietary Assessment. Washington, DC: National Academies Press.

6. Institute of Medicine (2002) Standing Committee on the Scientific Evaluation of Dietary Reference Intakes. Dietary Reference Intakes for Energy, Carbohydrate, Fiber, Fat, Fatty Acids, Cholesterol, Protein, and Amino Acids. Washington, DC: National Academies Press.

7. Institute of Medicine (2000) Food and Nutrition Board. Dietary Reference Intakes for Vitamin C, Vitamin E, Selenium, and Carotenoids. Washington, DC: National Academies Press.

8. Institute of Medicine (2011) Dietary Reference Intakes (DRIs): Tolerable Upper Intake Levels, Vitamins and Elements. Food and Nutrition Board. Washington, DC: National Academies Press.

9. Bai C, Twyman RM, Farré G, et al. (2011) A golden era pro-vitamin A enhancement in diverse crops. In Vitro Cell Dev Biol Plant 47, 205-221.

10. Shaw GM, Schaffer D, Velie EM, et al. (1995) Periconceptional vitamin use, dietary folate, and the occurrence of neural tube defects. Epidemiology 6, 219-226.

11. Berry RJ \& Li Z (2002) Folic acid alone prevents neural tube defects: evidence from the China study. Epidemiology 13, $114-116$

12. Bailey RL, Dodd KW, Gahche JJ, et al. (2010) Total folate and folic acid intake from foods and dietary supplements 
in the United States: 2000-2006. Am J Clin Nutr 91, 231-237.

13. Pérez-Massot E, Banakar R, Gómez-Galera S, et al. (2013) The contribution of transgenic plants to better health through improved nutrition: opportunities and constraints. Genes Nutr 8, 29-41.

14. Christou P \& Twyman RM (2004) The potential of genetically enhanced plants to address food insecurity. Nutr Res Rev 17, 23-42.

15. Farré G, Ramessar K, Twyman RM, et al. (2010) The humanitarian impact of plant biotechnology: recent breakthroughs vs bottlenecks for adoption. Curr Opin Plant Biol 13, 219-225.

16. Zhu C, Sanahuja G, Yuan D, et al. (2013) Biofortification of plants with altered antioxidant content and composition: genetic engineering strategies. Plant Biotechnol J 11, 129-141.

17. Paine JA, Shipton CA, Chaggar S, et al. (2005) Improving the nutritional value of Golden Rice through increased pro-vitamin A content. Nat Biotechnol 23, 482-487.

18. Naqvi S, Zhu C, Farré G, et al. (2009) Transgenic multivitamin corn through biofortification of endosperm with three vitamins representing three distinct metabolic pathways. Proc Natl Acad Sci U S A 106, 7762-7767.

19. Dapcich V, Salvador Castell G, Ribas Barba L, et al (2004) Guía de la alimentación saludable (Guide to Healthy Eating). Madrid: Sociedad Española de Nutrición Comunitaria (Spanish Society of Community Nutrition).

20. Rodriguez-Amaya DB (1997) Carotenoids and food preparation: the retention of provitamin A carotenoids in prepared, processed, and stored foods. http://pdf.usaid.gov/ pdf_docs/PNACB907.pdf (accessed September 2013).

21. Hart DJ \& Scott KJ (1995) Development and evaluation of an HPLC method for the analysis of carotenoids in foods, and the measurement of the carotenoid content of vegetables and fruits commonly consumed in the UK. Food Chem 54, 101-111.

22. Howard LA, Wong A, Perry AK, et al. (1999) $\beta$-Carotene and ascorbic acid retention in fresh and processed vegetables. J Food Sci 64, 929-936.

23. Lin CH \& Chen BH (2005) Stability of carotenoids in tomato juice during processing. Eur Food Res Technol 221, $274-280$.

24. Gayathri GN, Platel K, Prakash J, et al. (2004) Influence of antioxidant spices on the retention of $\beta$-carotene in vegetables during domestic cooking processes. Food Chem 84, 35-43.

25. Carvalho LMJ, Oliveira ARG, Godoy RLO, et al. (2012) Retention of total carotenoid and $\beta$-carotene in yellow sweet cassava (Manihot esculenta Crantz) after domestic cooking. Food Nutr Res 56, 15788-15795.

26. Bernhardt S \& Schlich E (2006) Impact of different cooking methods on food quality: retention of lipophilic vitamins in fresh and frozen vegetables. J Food Eng 77, $327-333$.

27. Mazzeo T, N'Dri D, Chiavaro E, et al. (2011) Effect of two cooking procedures on phytochemical compounds, total antioxidant capacity and colour of selected frozen vegetables. Food Chem 128, 627-633.

28. Pomeranz Y (1992) Biochemical, functional, and nutritive changes during storage. In Storage of Cereal Grains and Their Products, pp. 65-141 [DB Sauer, editor]. St Paul, MN: American Association of Cereal Chemists.

29. Borrelli GM, De Leonardis AM, Platani C, et al. (2008) Distribution along durum wheat kernel of the components involved in semolina colour. $J$ Cereal Sci $\mathbf{4 8}$, $494-502$.
30. Zielinski H, Kozlowska H \& Lewczuk B (2001) Bioactive compounds in the cereal grains before and after hydrothermal processing. Innov Food Sci Emerg 2, 159-169.

31. Finocchiaro F, Ferrari B, Gianinetti A, et al. (2007) Characterization of antioxidant compounds of red and white rice and changes in total antioxidant capacity during processing. Mol Nutr Food Res 51, 1006-1019.

32. Kanematsu H, Ushigusa T, Maruyama T, et al. (1983) Comparison of tocopherol contents in crude and refined edible vegetable oils and fats by high performance liquid chromatography. J Jap Oil Chem Sot 32, 122-126.

33. Ortega-García J, Gámez-Meza N, Noriega-Rodriguez JA, et al. (2006) Refining of high oleic safflower oil: effect on the sterols and tocopherols content. Eur Food Res Technol 223, 775-779.

34. Lešková E, Kubíková J, Kováčiková E, et al. (2006) Vitamin losses: retention during heat treatment and continual changes expressed by mathematical models. I Food Compos Anal 19, 252-276.

35. Han JS, Kozukue N, Young KS, et al. (2004) Distribution of ascorbic acid in potato tubers and in home-processed and commercial potato foods. I Agric Food Chem 52, 6516-6521.

36. Azzini E, Vitaglione P, Intorre F, et al. (2010) Bioavailability of strawberry antioxidants in human subjects. $\mathrm{Br} J$ Nutr 104, 1165-1173.

37. Bassett MN \& Sammán NC (2010) Folate content and retention in selected raw and processed foods. Arch Latinoam Nutr 60, 298-305.

38. Stea TH, Johansson M, Jägerstad M, et al. (2006) Retention of folates in cooked, stored and reheated peas, broccoli and potatoes for use in modern large-scale service systems. Food Chem 101, 1095-1107.

39. Dang J, Arcot J \& Shrestha A (2000) Folate retention in selected processed legumes. Food Chem 68, 295-298.

40. Scott J, Rébeille F \& Fletcher J (2000) Folic acid and folates: the feasibility for nutritional enhancement in plant foods. J Sci Food Agric 80, 795-824.

41. D'Ambrosio C, Giorio G, Marino I, et al. (2004) Virtually complete conversion of lycopene into $\beta$-carotene in fruits of tomato plants transformed with the tomato lycopene $\beta$-cyclase (tlcy-b) cDNA. Plant Sci 166, 207-214.

42. Haroldsen VM, Chi-Ham CL, Kulkarni S, et al. (2011) Constitutively expressed DHAR and MDHAR influence fruit, but not foliar ascorbate levels in tomato. Plant Physiol Biochem 49, 1244-1249.

43. Díaz de la Garza RI, Gregory JF III \& Handson AD (2007) Folate biofortification of tomato fruit. Proc Natl Acad Sci U S A 104, 4218-4222.

44. Seo YS, Kim SJ, Harn CH, et al. (2011) Ectopic expression of apple fruit homogentisate phytyltransferase gene (MdHPT1) increases tocopherol in transgenic tomato (Solanum lycopersicum cv. Micro-Tom) leaves and fruits. Phytochemistry 72, 321-329.

45. Lenucci MS, Cadinu D, Taurino M, et al. (2006) Antioxidant composition in cherry and high-pigment tomato cultivars. J Agric Food Chem 54, 2606-2613.

46. Proteggente AR, Pannala AS, Paganga G, et al. (2002) The antioxidant activity of regularly consumed fruit and vegetables reflects their phenolic and vitamin C composition. Free Radic Res 36, 217-233.

47. Bekaert S, Storozhenko S, Mehrshahi P, et al. (2008) Folate biofortification in food plants. Trends Plant Sci 13, 28-35.

48. Berman J, Zhu C, Pérez-Massot E, et al. (2013) Can the world afford to ignore biotechnology solutions that address food insecurity? Plant Mol Biol 83, 5-19. 
49. Zhu C, Naqvi S, Breitenbach J, et al. (2008) Combinatorial genetic transformation generates a library of metabolic phenotypes for the carotenoid pathway in maize. Proc Natl Acad Sci U S A 105, 18232-18237.

50. Cho CM, Ko JH \& Cheong WJ (2000) Simultaneous determination of water-soluble vitamins excreted in human urine after eating an overdose of vitamin pills by a HPLC method coupled with a solid phase extraction. Talanta 51, 799-806.

51. Levine M, Conry-Cantilena C, Wang Y, et al. (1996) Vitamin $\mathrm{C}$ pharmacokinetics in healthy volunteers: evidence for a recommended dietary allowance. Proc Natl Acad Sci U S A 93, 3704-3709.

52. Smith D, Kim YI \& Refsum H (2008) Is folic acid good for everyone? Am J Clin Nutr 87, 517-533.

53. Hathcock JN, Hattan DG, Jenkins MY, et al. (1990) Evaluation of vitamin A toxicity. Am J Clin Nutr 52, 183-202.

54. Penniston KL \& Tanumihardjo SA (2006) The acute and chronic toxic effects of vitamin A. Am J Clin Nutr 83, 191-201.

55. Bramley P, Elmadfa I, Kafatos A, et al. (2000) Vitamin E. J Sci Food Agric 80, 913-938.

56. Kappus H \& Diplock AT (1992) Tolerance and safety of vitamin E: a toxicological position report. Free Radic Biol Med 13, 55-74.

57. Sizer F, Sienkiewicz F \& Whitney E (2008) In Nutrition: Concepts and Controversies, 11th ed., pp. 221-235 [F Sizer and $\mathrm{E}$ Whitney, editors]. Belmont: Thomson Wadworth.

58. EFSA Panel on Genetically Modified Organisms (GMO) (2010) Guidance on the environmental risk assessment of genetically modified plants. EFSA J 8, 1879 .

59. EFSA Panel on Genetically Modified Organisms (GMO) (2011) Scientific opinion on guidance for risk assessment of food and feed from genetically modified plants. EFSA J 9, 37.

60. Tang G, Qin J, Dolnikowski G, et al. (2009) Golden Rice is an effective source of vitamin A. Am J Clin Nutr 89, $1776-1783$.

61. Arjó G, Capell T, Matias-Guiu X, et al. (2012) Mice fed on a diet enriched with genetically engineered multivitamin corn show no sub-acute toxic effects and no sub-chronic toxicity. Plant Biotechnol J 10, 1026-1034.

62. Naqvi S, Farré G, Sanahuja G, et al. (2010) When more is better: multigene engineering in plants. Trends Plant Sci 15, 49-56.

63. Naqvi S, Zhu C, Farré G, et al. (2011) Synergistic metabolism in hybrid corn reveals bottlenecks in the carotenoid pathway and leads to the accumulation of extraordinary levels of the nutritionally important carotenoid zeaxanthin. Plant Biotechnol J 9, 384-393.

64. Tang G, Hu Y, Yin S, et al. (2012) $\beta$-Carotene in Golden Rice is as good as $\beta$-carotene in oil at providing vitamin A to children. Am J Clin Nutr 96, 658-664.

65. López AB, Van Eck J, Conlin BJ, et al. (2008) Effect of the cauliflower $\mathrm{Or}$ transgene on carotenoid accumulation and chromoplast formation in transgenic potato tubers. $J$ Exp Bot 59, 213-223.

66. Li L, Yang Y, Xu Q, et al. (2012) The Or gene enhances carotenoid accumulation and stability during post-harvest storage of potato tubers. Mol Plant 5, 339-352.

67. Hwang FS, Stacewicz-Sapuntzakis M \& Bowen PE (2012) Effects of heat treatment on the carotenoid and tocopherol composition of tomato. J Food Sci 77, C1109-C1114

68. Dietz JM \& Gould WA (1986) Effect of process stage and storage on retention of $\beta$-carotene in tomato juice. $J$ Food Sci 51, 847-848.
69. Nagra AS \& Khan S (1988) Vitamin A ( $\beta$-carotene) losses in Pakistani cooking. J Sci Food Agric 46, 249-251.

70. Olunlesi AT \& Lee CY (1979) Effect of thermal processing on the stereoizomerization of major carotenoids and vitamin A value of carrots. Food Chem 4, 311-318.

71. Kim HY \& Gerber LE (1988) Influence of processing on quality of carrot juice. Korean J Food Sci Technol 20, 683-690

72. Jayaraj J, Devlin R \& Punja Z (2008) Metabolic engineering of novel ketocarotenoid production in carrot plants. Transgenic Res 17, 489-501.

73. Li Y, Wang G, Hou R, et al. (2011) Engineering tocopherol biosynthetic pathway in lettuce. Biol Plantarum 55, 453-460.

74. Yoshida H, Hirooka N \& Kajimoto G (1990) Microwave energy effects on quality of some seed oils. J Food Sci 55, $1412-1416$.

75. Masková E, Rysová J, Fiedlerová V, et al. (1996) Stability of selected vitamins and minerals during culinary treatment of legumes. Potravinárské Védy UZPI 14, 321-328.

76. Jain AK \& Nessler CL (2000) Metabolic engineering of an alternative pathway for ascorbic acid biosynthesis in plants. Mol Breeding 6, 73-78.

77. Bulley S, Wright M, Rommens C, et al. (2012) Enhancing ascorbate in fruits and tubers through over-expression of the L-galactose pathway gene GDP-L-galactose phosphorylase. Plant Biotechnol J 10, 390-397.

78. Alvi S, Khan KM, Sheikh MA, et al. (2003) Effect of peeling and cooking on nutrients in vegetables. Pak J Nutr 2, 189-191.

79. Qin A, Shi Q \& Yu X (2011) Ascorbic acid contents in transgenic potato plants overexpressing two dehydroascorbate reductase genes. Mol Biol Rep 38, 1557-1566.

80. Golaszewska B \& Zalewski S (2001) Optimisation of potato quality in culinary process. Pol J Food Nutr Sci 10, 59-63.

81. Nunes ACS, Kalkmann DC \& Aragão FJL (2009) Folate biofortification of lettuce by expression of a codon optimized chicken GTP cyclohydrolase I gene. Transgenic Res 18, 661-667.

82. De la Parra C, Serna Saldivar SO \& Hai Liu R (2007) Effect of processing on the phytochemical profiles and antioxidant activity of corn for production of masa, tortillas, and tortilla chips. J Agric Food Chem 55, 4177-4183.

83. Li E \& Tso P (2003) Vitamin A uptake from foods. Curr Opin Lipidol 14, 241-247.

84. Jeanes YM, Hall WL, Ellard S, et al. (2004) The absorption of vitamin $\mathrm{E}$ is influenced by the amount of fat in a meal and the food matrix. BrJ Nutr 92, 575-579.

85. Hofmann AF (1999) Bile acids: the good, the bad, and the ugly. News Physiol Sci 14, 24-29.

86. Lodge JK (2005) Vitamin E bioavailability in humans. J Plant Physiol 162, 790-796.

87. Yonekura L \& Nagao A (2009) Soluble fibers inhibit carotenoid micellization in vitro and uptake by Caco-2 cells. Biosci Biotechnol Biochem 73, 196-199.

88. De Pee S, West CE, Permaesih D, et al. (1998) Orange fruit is more effective than are dark-green, leafy vegetables in increasing serum concentrations of retinol and $\beta$-carotene in schoolchildren in Indonesia. Am J Clin Nutr 68, $1058-1067$.

89. Van het Hof KH, Brouwer IA, West CE, et al. (1999) Bioavailability of lutein from vegetables is five times higher than that of $\beta$-carotene. Am J Clin Nutr 70, 261-268.

90. Traber MG \& Sies H (1996) Vitamin E in humans: demand and delivery. Annu Rev Nutr 16, 321-347.

91. Traber MG \& Arai H (1999) Molecular mechanisms of vitamin E transport. Annu Rev Nutr 19, 343-355. 
92. Harrison EH (2012) Mechanisms involved in the intestinal absorption of dietary vitamin A and provitamin A carotenoids. Biochim Biophys Acta 1821, 70-77.

93. Lobo GP, Hessel S, Eichinger A, et al. (2010) ISX is a retinoic acid-sensitive gatekeeper that controls intestinal $\beta, \beta$-carotene absorption and vitamin A production. FASEB $J \mathbf{2 4}$, $1656-1666$.

94. Van Bennekum A, Werder M, Thuahnai ST, et al. (2005) Class B scavenger receptor mediated intestinal absorption of dietary $\beta$-carotene and cholesterol. Biochemistry $\mathbf{4 4}$, 4517-4525.

95. Reboul E, Klein A, Bietrix F, et al. (2006) Scavenger receptor class B type I (SR-BI) is involved in vitamin E transport across the enterocyte. J Biol Chem 281, 4739-4745.

96. Bietrix F, Yan D, Nauze M, et al. (2006) Accelerated lipid absorption in mice overexpressing intestinal SR-BI. $J$ Biol Chem 281, 7214-7219.

97. During A \& Harrison EH (2007) Mechanisms of provitamin A (carotenoid) and vitamin A (retinol) transport into and out of intestinal Caco-2 cells. J Lipid Res 48, 2283-2294.

98. Borel P, Preveraud D \& Desmarchelier C (2013) Bioavailability of vitamin E in humans: an update. Nutr Rev 71, 319-331.

99. Voolstra O, Kiefer C, Hoehne M, et al. (2006) The Drosophila class B scavenger receptor ninaD-I is a cell surface receptor mediating carotenoid transport for visual chromophore synthesis. Biochemistry 45, 13429-13437.

100. Takada T \& Suzuki H (2010) Molecular mechanisms of membrane transport of vitamin E. Mol Nutr Food Res 54, 616-622.

101. Reboul E \& Borel P (2011) Proteins involved in uptake, intracellular transport and basolateral secretion of fat-soluble vitamins and carotenoids by mammalian enterocytes. Prog Lipid Res 50, 388-402.

102. Oram JF, Vaughan AM \& Stocker R (2001) ATP-binding cassette transporter A1 mediates cellular secretion of $\alpha$-tocopherol. J Biol Chem 276, 39898-39902.

103. Yonekura L \& Nagao A (2007) Intestinal absorption of dietary carotenoids. Mol Nutr Food Res 51, 107-115.

104. Lee SK \& Kader AA (2000) Preharvest and postharvest factors influencing vitamin $\mathrm{C}$ content of horticultural crops. Postharvest Biol Technol 20, 207-220.

105. Corti A, Casini AF \& Pompella A (2010) Cellular pathways for transport and efflux of ascorbate and dehydroascorbate. Arch Biochem Biophys 500, 107-115.

106. Malo C \& Wilson JX (2000) Glucose modulates vitamin C transport in adult human small intestinal brush border membrane vesicles. J Nutr 130, 63-69.
107. Carlsson S, Wiklund NP, Engstrand L, et al. (2001) Effects of $\mathrm{pH}$, nitrite, and ascorbic acid on nonenzymatic nitric oxide generation and bacterial growth in urine. Nitric Oxide $\mathbf{5}$, $580-586$.

108. Gregory JF (2001) Case study: folate bioavailability. J Nutr 131, 1376S-1382S.

109. McKillop DJ, McNulty H, Scott JM, et al. (2006) The rate of intestinal absorption of natural food folates is not related to the extent of folate conjugations. Am J Clin Nutr 84, $167-173$.

110. Storozhenko S, Navarrete O, Ravanel S, et al. (2007) Cytosolic hydroxymethyldihydropterine pyrophosphokinase/ dihydropteroate synthase from Arabidopsis thaliana: a specific role in early development and stress response. J Biol Chem 282, 10749-10761.

111. Pteiffer CM, Rogers LM, Bailey LB, et al. (1997) Absorption of folate from fortified cereal-grain products and of supplemental folate consumed with or without food determinate using a dual-label stable-isotope protocol. Am J Clin Nutr 66, 1388-1397.

112. Aufreiter S, Gregory JF III \& Pfeiffer CM (2009) Folate is absorbed across the colon of adults: evidence from cecal infusion of ${ }^{13} \mathrm{C}$-labeled [6S]-5-formyltetrahydrofolic acid. Am J Clin Nutr 90, 116-123.

113. Gregory JF, Williamson J, Liao JF, et al. (1998) Kinetic model of folate metabolism in nonpregnant women consuming $\left[{ }^{2} \mathrm{H}_{2}\right]$ folic acid: isotopic labeling of urinary folate and the catabolite para-acetamidobenzoylglutamate indicates slow, intake-dependent, turnover of folate pools. J Nutr 128, 1896-1906.

114. Gregory JF (1995) The bioavailability of folate. In Folate in Health and Disease, pp. 195-235 [LB Bailey, editor]. New York: Marcel Dekker.

115. Herbert V (1987) Recommended dietary intakes (RDI) of folate in humans. Am J Clin Nutr 45, 661-670.

116. Farré G, Sanahuja G, Naqvi S, et al. (2010) Travel advice on the road to carotenoids in plants. Plant Sci 179, 28-48.

117. Qaim M (2010) Benefits of genetically modified crops for the poor: household income, nutrition, and health. Nat Biotechnol 27, 552-557.

118. Stein AJ, Sachdev HPS \& Qaim M (2006) Potential impact and cost-effectiveness of Golden Rice. Nat Biotechnol 24, $1200-1201$.

119. Institute of Medicine (1998) Dietary Reference Intakes for Thiamin, Riboflavin, Niacin, Vitamin $B_{6}$, Folate, Vitamin $B_{12}$, Pantothenic Acid, Biotin, and Choline. Washington, DC: National Academies Press. 